\title{
Temporal coding affects transfer of serial and simultaneous inhibitors
}

\author{
JAMES C. DENNISTON, AARON P. BLAISDELL, and RALPH R. MILLER \\ State University of New York, Binghamton, New York
}

\begin{abstract}
In three experiments with rats, the temporal relationships under which a conditioned inhibitor would transfer its inhibitory potential to an independently trained excitor in a summation test were investigated. Each experiment varied the temporal relationship between the inhibitor and the transfer excitor at test (serial or simultaneous) and, in addition, manipulated either the inhibitor-training excitor (serial or simultaneous), training excitor-unconditioned stimulus (US) (trace or delay), or the transfer excitor-US (trace or delay) temporal relationships. Conditioned inhibition was found only when the no-US expectation evoked by the conditioned inhibitor was temporally aligned with the US expectation evoked by the transfer excitor, independent of whether the inhibitor was trained as a serial or simultaneous signal for US omission. Results are discussed in terms of the temporal coding hypothesis and the comparator hypothesis.
\end{abstract}

For many years, students of learning have been interested in the circumstances under which the inhibitory properties of a stimulus will transfer to other stimuli. Conditioned inhibitors may be established through several procedures, the most common of which is the procedure of Pavlov (1927). In Pavlov's procedure, a conditioned stimulus (CS) is simultaneously paired with an unconditioned stimulus (US) on some trials (e.g., A-US, where A represents the CS), whereas, on other trials, the CS and a second stimulus $(X)$ are simultaneously presented in the absence of reinforcement (e.g., XA -). Interspersed trials of this sort normally result in $\mathrm{X}$ becoming a conditioned inhibitor. The inhibitory properties of $\mathrm{X}$ can be assessed through a summation test with an independently trained excitor, in which an inhibitor reduces responding to a known excitor (i.e., negative summation), and through a retardation test, in which subsequent pairings of the inhibitor with the US result in retarded excitatory behavioral control by X, relative to a novel stimulus (Rescorla, 1969). The question of the content of learning in conditioned inhibition and, specifically, whether the same type of learning occurs during serial and simultaneous (Pavlovian) inhibition training has attracted much attention in recent years (see Holland, 1992, for a review). The present research addresses the specificity of what is learned during Pavlovian inhibition training.

Support for this research was provided by National Institute of Mental Health Grant 33881. The authors thank James Esposito and Christy Beneri for their assistance in collecting the data and Daniel Burger, Lisa Gunther, and Hernan Savastano for their comments on an earlier version of this manuscript. Correspondence concerning this article should be addressed to R. R. Miller, Department of Psychology, State University of New York, Binghamton, NY 13902-6000 (e-mail: rmiller@ binghamton.edu).

Note_Vincent M. LoLordo served as action editor for this paper.
One potential attribute of inhibitory associations that might affect transfer of inhibitory control is the temporal relationship between associates in both training and testing. Pavlov's (1927) initial observation of the inhibition of delay phenomenon, in which excitatory conditioned responding is restricted to the latter portion of a protracted CS (i.e., near the time at which the US is expected to be presented), suggests that animals can learn the temporal relationship between a CS and a US (see also Rescorla, 1967 , for an example of inhibition of delay with an aversive preparation). More recently, Roberts (1981), using the peak procedure, has demonstrated that maximal response rates on fixed-time schedules of reinforcement occur at the time at which the US is expected to be presented. In addition, Goddard (1995) provided evidence that animals can learn the temporal intervals between unsignaled US presentations. In his study, food USs were presented to animals at fixed intervals of time $(60 \mathrm{sec})$, during which magazine entries were recorded. Goddard observed that the animals increased their rate of magazine entry as the time of US delivery approached (Experiment 2), whereas, immediately following US presentations, the rate of magazine entry decreased (Experiment 1). These findings are reminiscent of Pavlov's inhibition of delay studies, except that punctate CSs were not presented. Instead, the animals appeared to be learning the temporal interval between successive US presentations and using this information to determine when to respond.

Temporal coding theories (Barnet, Arnold, \& Miller, 1991; Church, 1984; Desmond \& Moore, 1988; Gibbon \& Balsam, 1981; Killeen \& Fetterman, 1988; Matzel, Held, $\&$ Miller, 1988) have been used to explain the response deficits, relative to forward short-delay conditioning, that are observed following trace conditioning (Cole, Barnet, \& Miller, 1995), backward conditioning (Matzel et al., 1988), and simultaneous conditioning (Barnet et al., 1991), as well as the influence of temporal variables in overshad- 
owing (Blaisdell, Denniston, \& Miller, 1998) and blocking (Barnet, Grahame, \& Miller, 1993). Recently, the utility of temporal coding theories has been extended to phenomena beyond response deficits. For example, Barnet, Cole, and Miller (1997) found that, following backward conditioning (i.e., US $\rightarrow \mathrm{S} 1$ ) and subsequent S2 $\rightarrow \mathrm{S} 1$ second-order pairings, $\mathrm{S} 2$ elicited robust conditioned responding, despite weak first-order S1 responding.

Barnet et al. (1997) explained their findings in terms of the temporal coding hypothesis (Barnet et al., 1991; Blaisdell et al., 1998, Cole et al., 1995; Denniston, Cole, \& Miller, 1998; Matzel et al., 1988; Miller \& Barnet, 1993), which states that (1) temporal contiguity is both necessary and sufficient for learning to occur; (2) associations not only link events in memory, but also incorporate the temporal relationship between the CS and the US as part of the encoded memory (i.e., the subjects form temporal maps that link events in memory); (3) the topography and timing of the conditioned response are in part determined by these temporal maps (i.e., the temporal maps determine how and when to respond); and (4) animals can integrate temporal maps when elements common to these maps are presented together, even when the elements were trained separately. Specifically, Barnet et al.'s results suggest that animals can learn the temporal order of cues, such that $S 2$, despite being paired with a backward CS, can, with appropriate temporal parameters, have a forward (i.e., predictive) relationship with the US through integration of the S2-S1 and US-S1 temporal relationships. This forward relationship resulted in robust conditioned responding to S2.

Recent studies of conditioned inhibition (Barnet \& Miller, 1996; Denniston et al., 1998) have found that the temporal relationship between a conditioned inhibitor and its omitted US is critical in determining when conditioned inhibition will be observed in negative summation tests. That is, in both reports, maximal conditioned inhibition was observed only when the time at which the inhibitor predicted the absence of the US (as conveyed by the temporal relationships between the conditioned inhibitor and the training excitor and between the training excitor and the US) was congruent with the time at which the transfer excitor predicted the presentation of the US (as conveyed by the temporal relationship between the transfer excitor and the US). When either of these temporal intervals was manipulated in such a way that the inhibitor and the transfer excitor signaled US absence and US presence, respectively, at different points in time, less inhibition was observed.

Barnet and Miller (1996) manipulated two variablesthe training excitor-US temporal relationship (serial or simultaneous) and the inhibitor-training excitor temporal relationship (serial or simultaneous). In their study, maximal inhibition was demonstrated when the time at which the US was expected to be omitted (on the basis of information provided by the conditioned inhibitor) was congruent with the time at which the US was expected to be presented (on the basis of information provided by the transfer excitor). Denniston et al. (1998) extended the work of Barnet and Miller by studying a third temporal variable that might influence when a conditioned inhibitor would transfer its control to a transfer excitor-specifically, the transfer excitor-US temporal relationship. In Denniston et al.'s two experiments, they manipulated the transfer excitor-US temporal relationship, plus one or the other of the two temporal variables that had been manipulated by Barnet and Miller. As in the Barnet and Miller study, the greatest inhibition was observed on summation tests in which the omission of the US signaled by the inhibitor was that expected at the same point in time as was US presentation on the basis of presentation of the transfer excitor.

Collectively, the studies by Barnet and Miller (1996) and by Denniston et al. (1998) support the view that temporal coding is an important factor in determining when conditioned inhibition will transfer to an independently trained excitor. However, the work of Holland and his colleagues provides conflicting results. Holland and Lamarre (1984) investigated the ability of simultaneous and serial negative features to transfer their inhibitory control to various target CSs. In their Experiment 1, rats received training on one of two feature-negative discriminations. Each discrimination was composed of two trial typesreinforced presentations of the target $\mathrm{CS}$ alone and nonreinforced presentations of the feature and the target CS. On the nonreinforced trials, the feature preceded the target CS for Group Serial, whereas the feature was presented simultaneously with the target CS for Group Simultaneous. At test, the feature was presented both serially and simultaneously with its original training target CS or with another excitatory CS that was not part of the featurenegative discrimination. Thus, the temporal relationship between the feature and its target CS and whether the feature was tested with its training target CS or a different (i.e., transfer) target CS were factorially tested. Their results indicated that the simultaneous feature reduced responding to both the original and the transfer target CSs when testing maintained the temporal relationship established during training (i.e., a simultaneous test) but not when the temporal relationship was varied (i.e., the serial test). However, the serial feature was able to modulate responding to its target $\mathrm{CS}$ when testing was conducted either serially or simultaneously but was unable to modulate responding to the transfer target $\mathrm{CS}$, regardless of the temporal arrangement at test. Whereas the results from Group Simultaneous are fully consistent with the temporal coding hypothesis, the absence of modulation of responding to transfer target CSs and the lack of temporal specificity of transfer in Group Serial are problematic for a temporal coding hypothesis account.

These findings raise the question of what circumstances will facilitate the transfer of a negative serial feature to other target CSs. Lamarre and Holland (1987, Experiment 1) tested whether a serial feature would modulate responding to a consistently reinforced excitor, a target that was trained as part of a simultaneous feature-negative discrimination, or a target from another serial feature- 
negative discrimination. Their results indicated substantial transfer to the serial target, significant transfer to the simultaneous target (that was significantly less than that observed with the serial target), and no transfer to the consistently reinforced excitor. In their Experiment 2, Lamarre and Holland asked whether it is the ambiguous training experience of the target CS from the other feature-negative discrimination that promoted transfer by the feature in question. In order to answer this question, they tested transfer of a serial negative feature to either a consistently reinforced or a partially reinforced excitor (Experiment 2A) or an extinguished and then retrained excitor (Experiment 2B). In both experiments, little transfer to any of the target CSs was observed. However, small but significant transfer was observed in one group that received training on two feature-negative problems when testing was conducted with the partially reinforced transfer excitor. On the basis of these findings, Holland and his colleagues have concluded that serial negative features will best transfer to target CSs that are also trained in a feature-negative discrimination.

Although Holland and his colleagues have frequently failed to observe substantial transfer of serial featurenegative cues to independently trained excitors (see, e.g., Holland, 1989; Holland \& Lamarre, 1984; Lamarre \& Holland, 1987), Barnet and Miller (1996) and Denniston et al. (1998) have successfully obtained transfer of behavioral control by serial negative features. One procedural difference that exists between the studies of Holland and those of Barnet and Miller and Denniston et al. is the method of testing. Holland and Lamarre (1984, Experiment 1) trained two groups of subjects on either a serial or a simultaneous feature-negative discrimination and then tested the subjects from each group, using both a serial and a simultaneous test with the original target CS and with a transfer excitatory CS. Thus, for each group, testing occurred with both the original and a transfer target CS, with the same and different temporal arrangements at test. They found that the serial feature modulated responding to the original target CS on both the serial and the simultaneous tests but failed to modulate responding to the transfer target CS on both types of tests. Furthermore, the simultaneous feature was able to modulate responding to both the original target and the transfer target only when testing was conducted with a simultaneous test. Barnet and Miller and Denniston et al. tested with simultaneous summation tests with independently trained transfer excitors. Moreover, to manipulate the different temporal expectancies of US presence and absence, Barnet and Miller trained their serial and simultaneous inhibitors with training excitors that were either serially or simultaneously paired with the US. In the Denniston et al. study, the transfer excitor-US temporal relationship was also manipulated in order to produce expectancies for US omission and presentation that were either temporally congruent or temporally incongruent. Exactly which of these differences from the procedures of Holland et al. is responsible for the conflicting results is not clear at this time.

The present series of studies sought to extend the findings of Barnet and Miller (1996) and Denniston et al. (1998) by using both simultaneous and serial transfer tests, as in the studies by Holland and his colleagues (e.g., Holland, 1989; Holland \& Lamarre, 1984). In each of the present studies, there were four temporal variables which could be manipulated: (1) the inhibitor-training excitor temporal relationship (simultaneous or serial); (2) the training excitor-US temporal relationship (trace or delay); (3) the transfer excitor-US temporal relationship (trace or delay); and (4) the inhibitor-transfer excitor temporal relationship at test (simultaneous or serial). Because Barnet and Miller manipulated variables 1 and 2 in their study and Denniston et al. manipulated variables 1 and 3 and 2 and 3 in their studies, while holding the other variables constant, the present study sought to manipulate variable 4 with respect to each of the remaining variables, in three separate experiments. In Experiment 1, we manipulated variables 1 (the inhibitor-training excitor relationship) and 4; in Experiment 2, we manipulated variables 2 (the training excitor-US temporal relationship) and 4; and in Experiment 3, we manipulated variables 3 (the transfer excitor-US temporal relationship) and 4-while, in each study, holding the other two variables constant. On the basis of the temporal coding hypothesis, we expected maximal conditioned inhibition to be observed when the time at which the inhibitor predicted omission of the US was the same as the time at which the transfer excitor signaled presentation of the US, regardless of whether the inhibitor was trained simultaneously or serially with its training excitor. That is, according to the temporal coding hypothesis, the manner in which an inhibitor is trained (simultaneous or serial) and whether testing is conducted serially or simultaneously are not critical in determining when inhibition will be observed, per se. Rather, only simultaneous temporal expectancies for US presentation (provided by the transfer excitor) and for omission (provided by the inhibitor) will produce maximal conditioned inhibition, as assessed on a summation test.

\section{EXPERIMENT 1}

In Experiment 1, the putative temporal maps generated through conditioned inhibition training and transfer excitor training were varied by manipulating the inhibitortraining excitor temporal relationship (serial or simultaneous) and the inhibitor-transfer excitor temporal relationship at test (serial or simultaneous), while holding constant the training excitor-US temporal relationship (serial) and the transfer excitor-US temporal relationship (serial). All the subjects received training that established a single CS (A) as a signal for US presentation. CS A was trained as a delay excitor with no gap between CS termination and US onset (i.e., $\mathrm{A} \stackrel{0}{\rightarrow}$ US, where 
0 represents the gap between CS termination and US onset). Additionally, two conditioned inhibitors ( $X$ and $\mathrm{Y}$ ) were trained as signals for US omission. Inhibitor $\mathrm{X}$ was trained as a simultaneous inhibitor with A (i.e., XA-), and inhibitor $Y$ was trained as a serial inhibitor, for which termination of $\mathrm{Y}$ coincided with onset of $\mathrm{A}$ (i.e., $\mathrm{Y} \rightarrow$ A-). Prior to summation testing, a transfer excitor (C) was trained as a delay excitor (i.e., $\mathrm{C} \stackrel{0}{\rightarrow}$ US), for which $\mathrm{CS}$ termination coincided with US onset on reinforced trials. Partial reinforcement of transfer excitor $\mathrm{C}$ was intended to provide the excitor with an ambiguous training history in order to facilitate transfer of inhibitory control by the serial inhibitor. Our basis for choosing partial reinforcement stems from Lamarre and Holland (1987, Experiment 2A), who found that, following training of two serial feature-negative discriminations, small but reliable transfer was observed to a partially reinforced excitor, and from Rescorla (1985), who found enhanced transfer by a serial feature-positive cue when the target CS had been reinforced, extinguished, and then retrained. However, it is important to note that both Barnet and Miller (1996) and Denniston et al. (1998) found reliable transfer by serial inhibitors when the target excitor had been consistently reinforced. Furthermore, the use of par- tial reinforcement in training of the transfer excitors does not change the prediction of the temporal coding hypothesis - namely, that inhibition should be temporally specific. Testing occurred during a single summation test, in which the ability of the inhibitors to reduce responding to the transfer excitor was assessed with both serial and simultaneous tests. The simultaneous test consisted of presenting inhibitor $\mathrm{X}$ or $\mathrm{Y}$ with transfer excitor $\mathrm{C}$ (common onset and termination--i.e., $\mathrm{XC}$ or $\mathrm{YC}$ ), whereas the serial test consisted of presenting inhibitor $\mathrm{X}$ or $\mathrm{Y}$ for $5 \mathrm{sec}$, followed immediately $(0 \mathrm{sec})$ by the transfer excitor (i.e., $\mathrm{X} \stackrel{0}{\rightarrow} \mathrm{C}$ or $\mathrm{Y} \stackrel{0}{\rightarrow} \mathrm{C}$ ).

If subjects encode the temporal relationships between stimuli and integrate the putative temporal maps to determine responding when elements common to these maps are presented together, as the temporal coding hypothesis claims, maximal conditioned inhibition would be expected when inhibitor $\mathrm{X}$ is tested simultaneously with the transfer excitor and when inhibitor $Y$ is presented serially with the transfer excitor. These predictions can be derived from superimposing the temporal maps generated during conditioned inhibition training and transfer excitor training (see Figure 1). When testing is conducted with simultaneous presentation of the inhibitor and

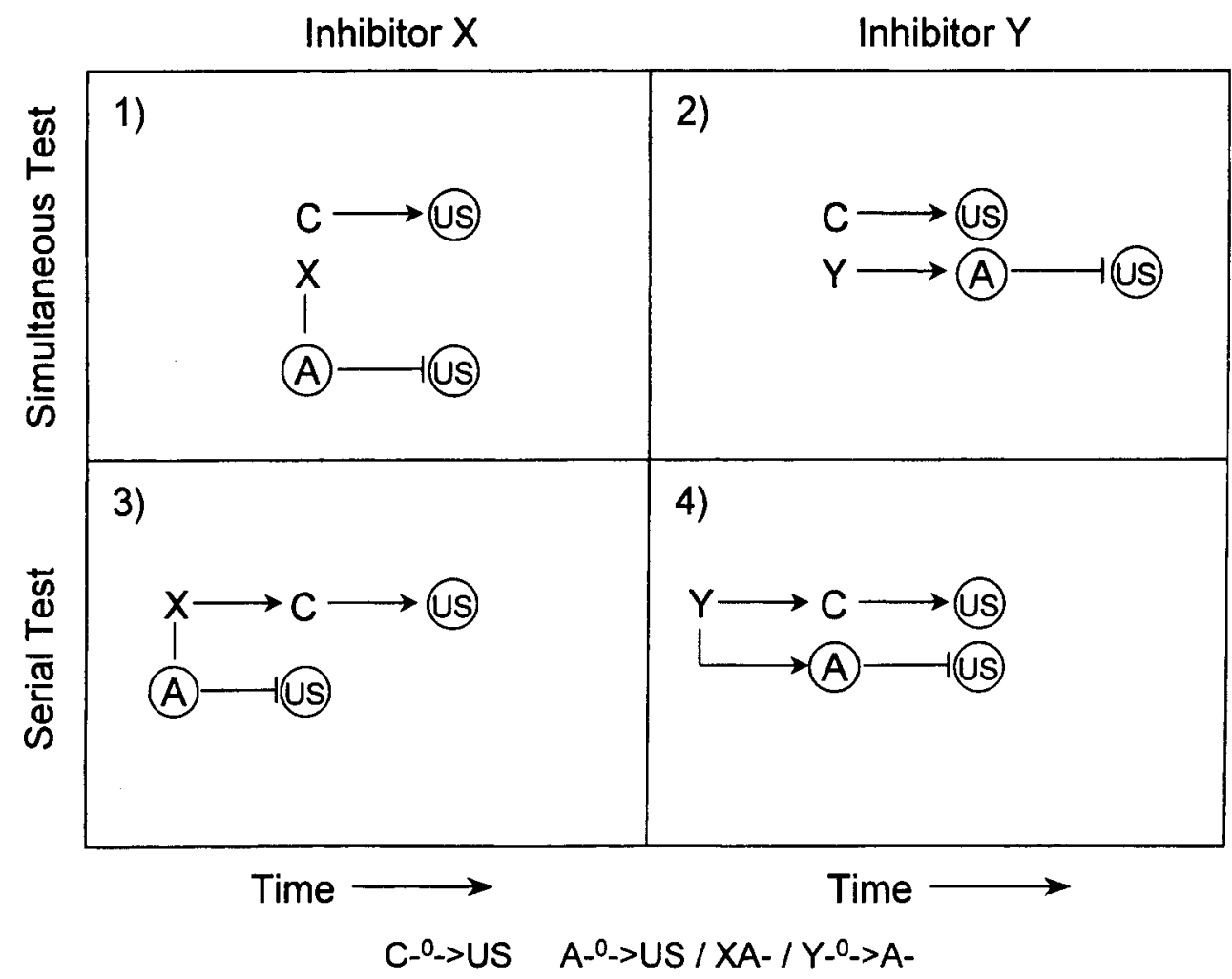

Figure 1. Hypothetical expectancies generated at test, as a result of conditioned inhibition training and transfer excitor training. Horizontal lines indicate a forward expectancy. Horizontal lines with an arrow represent an expected unconditioned stimulus (US); horizontal lines ending with a cross bar indicate that an otherwise expected US will be omitted. Vertical lines indicate a simultaneous expectancy. Maximal inhibition is hypothesized to occur when the time at which the US is expected is congruent with the time at which the US is signaled to be omitted. Panel 1: simultaneous XC test; Panel 2: simultaneous YC test; Panel 3: serial $X \rightarrow C$ test; Panel 4: serial $Y \rightarrow C$ test. 
the transfer excitor (see Figure 1, Panels 1 and 2), only inhibitor X signals the absence of the US at the same time as transfer excitor $\mathrm{C}$ signals presentation of the US. Conversely, with a serial test (see Figure 1, Panels 3 and 4), only inhibitor $\mathrm{Y}$ signals the absence of the US at the same time as transfer excitor $\mathrm{C}$ signals presence of the CS. These predictions, derived from the temporal coding hypothesis, differ from those generated on the basis of Holland and Lamarre's (1984) results. On the basis of their conclusions, no transfer by inhibitor $Y$ ought be observed, regardless of the temporal relationship at test, as serial inhibitors (features) generally failed to modulate responding to simple excitors, whereas transfer of X's inhibitory control ought to be observed, provided the temporal parameters are maintained at test.

\section{Method}

Subjects. The subjects were 30 male and 30 female experimentally naive Sprague-Dawley rats. Body weights ranged from 214 to $309 \mathrm{~g}$ for males and from 161 to $209 \mathrm{~g}$ for females. The animals were individually housed in standard hanging stainless steel wire-mesh cages in a vivarium maintained on a 16:8-h light:dark cycle. All training occurred approximately midway through the light portion of the cycle. The subjects were allowed free access to food in their home cages, whereas access to water was gradually decreased to $10 \mathrm{~min}$ of access per day before the initiation of the experiment. All the subjects were handled for $30 \mathrm{sec}$ three times per week from weaning until the initiation of the study.

Apparatus. Two types of experimental chambers were used. Chamber $\mathrm{R}$ was rectangular in shape and measured $22.75 \times 8.25 \times$ $13.0 \mathrm{~cm}$ (length $\times$ width $\times$ height). The walls and ceiling of the chamber were constructed of clear Plexiglas, and the floors consisted of stainless steel rods measuring $0.48 \mathrm{~cm}$ in diameter, spaced $1.5 \mathrm{~cm}$ center-to-center. The rods were connected by NE2-neon bulbs that allowed for the delivery of constant-current footshock produced by a high-voltage ac circuit in series with a $1.0-\mathrm{M} \Omega$ resistor. Each of six copies of Chamber $\mathrm{R}$ was housed in a separate sound- and light-attenuating environmental enclosure. Chamber $R$ was dimly illuminated by a $2.0-\mathrm{W}$ (nominal at $120 \mathrm{~V}$ ac) houselight driven at $60 \mathrm{~V}$ ac. The bulb was located on the inside wall of the environmental enclosure, approximately $30 \mathrm{~cm}$ from the center of the experimental chamber. Background noise, mostly from a ventilation fan, was $74 \mathrm{~dB}(\mathrm{C})$ re. SPL.

Chamber $V$ was a $25.5-\mathrm{cm}$-long box in the shape of a vertical truncated-V. The chamber was $28 \mathrm{~cm}$ high, $21 \mathrm{~cm}$ wide at the top, and narrowed to $5.25 \mathrm{~cm}$ wide at the bottom. The ceiling was constructed of clear Plexiglas; the front and back walls were black Plexiglas; and the side walls were stainless steel. The floor consisted of two $25.5-\mathrm{cm}$-long parallel metal plates, each $2 \mathrm{~cm}$ wide and separated by a $1.25-\mathrm{cm}$ gap. A constant-current footshock could be delivered through the metal walls and floor of the chamber. Each of six copies of Chamber $V$ was housed in a separate sound- and light-attenuating enclosure. Chamber $\mathrm{V}$ was illuminated by a $7-\mathrm{W}$ (nominal at $120 \mathrm{~V} \mathrm{ac}$ ) bulb driven at $60 \mathrm{~V}$ ac. The bulb was mounted on the inside wall of the environmental enclosure, approximately $30 \mathrm{~cm}$ from the center of the experimental chamber, with the light entering the chamber primarily by reflection from the ceiling of the environmental enclosure. The light intensities in Chambers $R$ and $V$ were approximately equal, despite the discrepancy in the light bulbs used, because of differences between the chambers in the opaqueness of the chamber walls.

Chambers $\mathrm{R}$ and $\mathrm{V}$ could each be equipped with a water-filled lick tube. When inserted, the lick tube extended about $1 \mathrm{~cm}$ into a cylindrical drinking recess that was set into one of the narrow Plexiglas walls of the chamber. Each drinking recess was left-right centered, with its bottom $1.75 \mathrm{~cm}$ above the floor of the chamber. The recess was $4.5 \mathrm{~cm}$ in diameter and $5 \mathrm{~cm}$ deep. An infrared photobeam was projected horizontally across the recess, $1 \mathrm{~cm}$ in front of the lick tube. In order to drink from the lick tube, the subjects had to insert their heads into the recess, thereby breaking the photobeam. By this means, we could monitor exactly when the subjects were accessing the lick tube. Three speakers, mounted on separate walls in each enclosure, could deliver the following auditory cues: a 6-sec click train, a white noise, and a high-frequency tone (compound of 3000 and $3200 \mathrm{~Hz}$ ), each $8 \mathrm{~dB}(\mathrm{C})$ above the ambient background of $74 \mathrm{~dB}(\mathrm{C})$. Each chamber could also provide a flashinglight stimulus $(0.17 \mathrm{sec}$ on $/ 0.17 \mathrm{sec}$ off $)$. In Chamber $R$, the flashing light was a $25-\mathrm{W}$ bulb (nominal at $120 \mathrm{~V} \mathrm{ac}$ ), driven at $60 \mathrm{~V} \mathrm{ac}$, whereas the flashing light in Chamber $V$ was a 100 -W bulb (nominal at $120 \mathrm{~V} \mathrm{ac}$ ), driven at $60 \mathrm{~V}$ ac. The bulbs were located on the back wall of each environmental chest. All CSs were $5 \mathrm{sec}$ in duration, and the US was a $0.5-\mathrm{sec}, 1.2 \mathrm{~mA}$ footshock.

Procedure. There were three critical phases in this experiment. In the first phase, all the subjects received conditioned inhibition training consisting of $\mathrm{A} \stackrel{0}{\rightarrow} \mathrm{US}, \mathrm{XA}-$, and $\mathrm{Y} \stackrel{0}{\rightarrow} \mathrm{A}-$ pairings, in which $A$ represents the training excitor. The superscript 0 represents the interval between CS termination and US onset. Thus, CS A served as a delay CS (i.e., there was no gap between CS termination and onset of the US). Inhibitor $X$ was simultaneously paired with training excitor $\mathrm{A}$ (i.e., $\mathrm{XA}-$ ), whereas inhibitor $\mathrm{Y}$ was serially paired with $A$ (i.e., $\mathrm{Y}^{0} \rightarrow A-$ ). The second phase of the experiment established $\mathrm{C}$ as a delay $\mathrm{CS}$ for US presentation (i.e., $\mathrm{C} \stackrel{0}{\rightarrow} \mathrm{US}$ ). The third phase of the experiment consisted of summation testing with the transfer excitor, during which the potential of $X$ and $Y$ to reduce responding to the transfer excitor was assessed in both serial and simultaneous tests.

Conditioned inhibition training occurred in Context CI Train, which was Chamber $\mathrm{V}$ for half of the subjects in each test condition and Chamber $\mathrm{R}$ for the remaining subjects. Context Transfer Train was used for transfer excitor training. This context was Chamber $\mathrm{V}$ or R, whichever type chamber had not been used for inhibition training. Finally, summation testing occurred in Context Test, which was created by testing animals in a different example of Chamber $R$ than that which had been used for either inhibition or transfer excitor training. Context Test was further differentiated from Chamber $\mathrm{R}$ by the addition of a Plexiglas floor plate that covered the grid floor and an odor cue (one drop of $98 \%$ methyl salicylate placed on a wooden block inside the environmental enclosure), as well as by turning off the houselight that otherwise illuminated Chamber R. Different contexts were used between phases so that an associatively neutral context was present at the time of transfer excitor training and again at testing. This ensured that any reduction in responding to the transfer excitor at test could only be attributed to inhibition training and not to contextual associations acquired during inhibition or transfer excitor training.

Following the completion of inhibition and transfer excitor training, a summation test was conducted with each subject. For the purpose of testing, the subjects were randomly assigned to one of five test conditions ( $n=12$ ), counterbalanced for sex. One condition was tested with the transfer excitor alone, whereas the other four conditions were tested with one of the inhibitors ( $\mathrm{X}$ or $\mathrm{Y}$ ) in conjunction with the transfer excitor $(C)$, in a serial or simultaneous test. During the serial test, $\mathrm{X}$ or $\mathrm{Y}$ was presented serially with $\mathrm{C}$, so that termination of $X$ or $Y$ coincided with onset of $C$, whereas in the simultaneous test, $\mathrm{X}$ or $\mathrm{Y}$ had a common onset with $\mathrm{C}$.

Acclimation. Acclimation to the experimental chambers was conducted in Context CI Train on Day 1, Context Transfer Train on Day 2, and Context Test on Day 3. During these daily 30-min sessions, water-filled lick tubes were available, and no punctate stim- 
uli were presented. This phase of the experiment served to establish a stable baseline level of drinking behavior, departure from which would serve as the dependent variable during testing.

Conditioned inhibition training. Following acclimation, the water-filled lick tubes were removed from all chambers. Inhibition training was conducted in Context CI train during daily 60-min sessions on Days 4-24 and 31-33. During each of these 24 sessions, all the subjects received six $\mathrm{A} \stackrel{0}{\rightarrow} \mathrm{US}$, six XA-, and six $\mathrm{Y} \stackrel{0}{\rightarrow} \mathrm{A}-$ trials. The flashing light served as CS A, and the high-frequency complex tone and the white noise stimuli served as inhibitors $\mathrm{X}$ and $\mathrm{Y}$, counterbalanced within test conditions. All the sessions began with a reinforced trial; the remaining reinforced and nonreinforced trials were pseudorandomly distributed within the session. The mean intertrial interval (CS onset to CS onset) was $3 \mathrm{~min}$, with a range of 1.5-4.5 $\mathrm{min}$. Three different running schedules, which differed with respect to trial order, were alternated, using an $\mathrm{A}, \mathrm{B}, \mathrm{C}, \mathrm{C}, \mathrm{B}$, A pattern between days.

Transfer excitor training. All the subjects received transfer excitor training on Days 25-30, which consisted of four reinforced $\mathrm{C} \stackrel{0}{\rightarrow}$ US trials and four nonreinforced $\mathrm{C}$ - trials during each of the six daily 60-min sessions in Context Transfer Train. The click train served as CS C. Reinforced and nonreinforced trials were pseudorandomly distributed within each session and were separated by a 7 -min mean intertrial interval that ranged from 3 to $11 \mathrm{~min}$. All the transfer excitor training sessions began with a reinforced trial. Two different running schedules, which differed in trial order, were alternated, using an A, B, B, A pattern between days.

Reacclimation. On Days 34 and 35, all the subjects were reacclimated to Context Test during 30-min daily sessions. During these reacclimation sessions, the water-filled lick tubes were returned to the chambers in order to stabilize baseline drinking following any disruption produced by the footshock USs.

Testing. On Day 36, all the animals were tested for suppression of ongoing drinking in the presence of the test stimuli in Context Test. During this test session, the animals were allowed to drink from the lick tubes for 5 cumulative sec, after which the target stimuli were presented. Thus, all the subjects were drinking at the moment of test stimuli onset. For the subjects tested with the transfer excitor alone or with the simultaneous test compound (XC or $\mathrm{YC}$ ), the time to complete an additional 5 cumulative sec of licking in the presence of the test stimuli was recorded. For the subjects tested with the serial test $(\mathrm{X} \stackrel{0}{\rightarrow} \mathrm{C}$ or $\mathrm{Y} \stackrel{0}{\rightarrow} \mathrm{C}$ ), following completion of 5 cumulative sec of drinking in the absence of any test stimuli, the inhibitor (X or $\mathrm{Y}$ ) was presented for $5 \mathrm{sec}$, followed at its termination by onset of the transfer excitor. The time to complete an additional 5 cumulative sec of licking in the presence of the transfer excitor alone was recorded. An 11-min ceiling was imposed on the suppression scores. In addition, any subject taking more than $60 \mathrm{sec}$ to complete its first 5 cumulative sec of drinking (prior to CS onset), thus showing a reluctance to drink in the test context, was scheduled to be eliminated from the data analysis. In practice, no subjects had to be eliminated for this reason from Experiment 1.

Prior to statistical analysis, all the suppression scores were converted to $\log$ (base 10 ) scores, in order to permit the use of parametric statistics. An alpha level of .05 was adopted for all statistical tests in each experiment.

\section{Results and Discussion}

The central findings from this study were that less suppression (i.e., behavior indicative of greater inhibition of conditioned suppression) was observed in the subjects tested with the simultaneous compound $\mathrm{XC}$, but not $\mathrm{YC}$, and with the serial compound $\mathrm{Y} \stackrel{0}{\rightarrow} \mathrm{C}$, but not $\mathrm{X} \stackrel{0}{\rightarrow} \mathrm{C}$, relative to the transfer excitor $\mathrm{C}$ alone. Thus, the greatest conditioned inhibition was observed when the temporal expectation of US presentation, evoked by the transfer excitor, corresponded temporally with the no-US expectation evoked by the inhibitor. Figure 2 depicts the mean

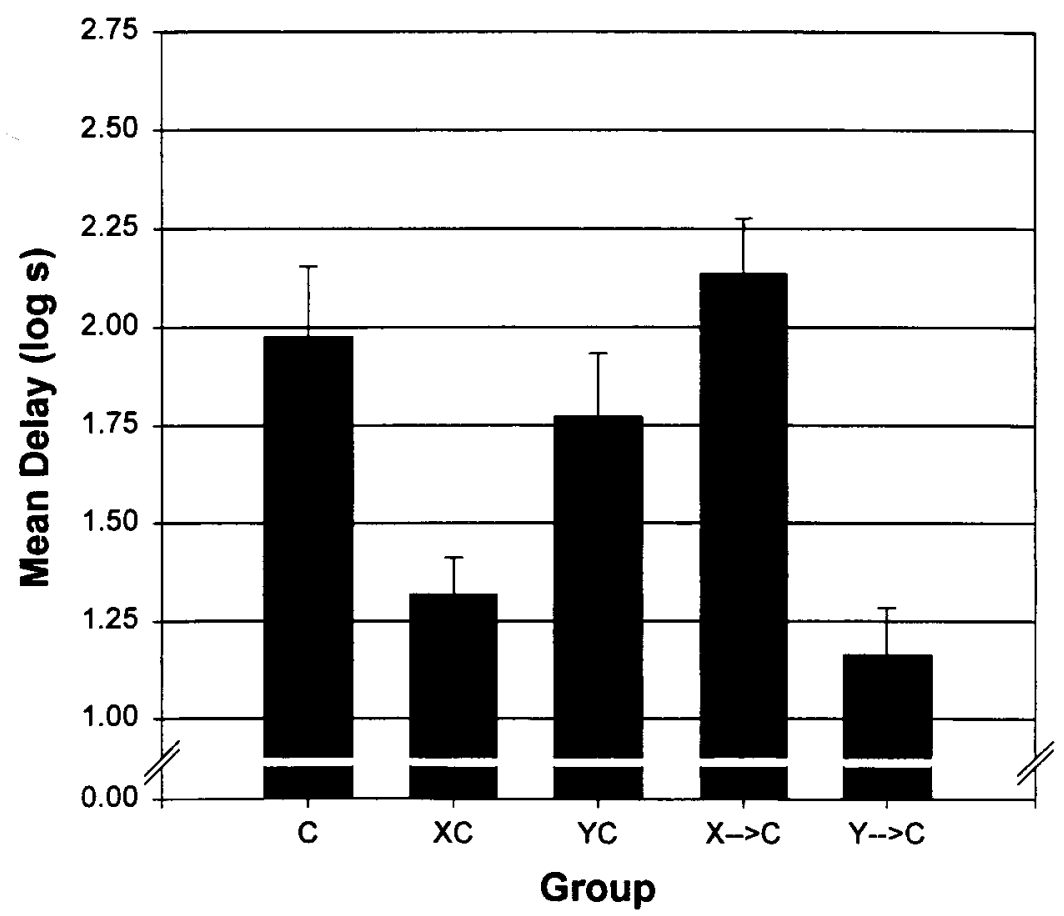

Figure 2. Mean times to complete 5 cumulative sec of drinking in the presence of the test stimuli in Experiment 1. Greater scores indicate less conditioned inhibition. Bars represent standard error of means. 
time to complete the 5 cumulative sec of drinking in the presence of the test stimuli.

These findings were confirmed with the following statistical analyses. Prior to analyzing the conditioned suppression to the CSs, we first looked for differences between test conditions in the mean log time to complete the 5 cumulative sec of drinking immediately preceding onset of the test stimuli. Any observed difference in baseline drinking would suggest a potential confound arising from differential tendencies to drink in the test context in the absence of the test stimuli. No differences were found in the time to complete 5 cumulative sec of pre-CS drinking in this experiment or in Experiments 2 and 3 (all $F \mathrm{~s}<1$ ). Having found no differences in baseline drinking, we then analyzed conditioned suppression in the presence of the test stimuli. A one-way analysis of variance (ANOVA) with test stimulus as the factor was conducted on the suppression scores from the five test conditions. The ANOVA revealed a main effect of test stimulus $[F(4,55)=$ $8.71, p<.001]$. Planned comparisons using the error term from the ANOVA were conducted on the suppression scores of select test conditions. Comparisons of the levels of responding between the subjects tested with the transfer excitor alone and those tested with the simultaneous compounds $\mathrm{XC}$ and $\mathrm{YC}$ revealed less conditioned responding in Test Condition XC than in $\mathrm{C}[F(1,55)=$ $10.74, p<.001]$ and no difference in responding between Test Conditions $Y C$ and $C[F(1,55)=1.02, p>.30]$. Comparisons of suppression scores for subjects tested with $C$ alone versus those tested with serial compounds $X \stackrel{0}{\rightarrow} C$ and $\mathrm{Y} \stackrel{0}{\rightarrow} \mathrm{C}$ revealed no difference between responding to $\mathrm{C}$ alone and to $\mathrm{X} \stackrel{0}{\rightarrow} \mathrm{C}[F(1,55)<1, p>.40]$ and a significant reduction in responding to $\mathrm{Y} \rightarrow \mathrm{C}$, relative to $\mathrm{C}$ $[F(1,55)=16.38, p<.001]$. Further comparison contrasted the differences in responding to the two simultaneous compounds and the two serial compounds. These comparisons found the mean latency to complete the lick requirement for $\mathrm{Y} \rightarrow \mathrm{C}$ to be significantly less than that observed for $\mathrm{X} \stackrel{0}{\rightarrow} \mathrm{C}[F(1,55)=23.48, p<.001]$ and the mean latency to $\mathrm{XC}$ to be reliably less than that to $\mathrm{YC}$ $[F(1,55)=5.14, p<.05]$. To better appreciate the differences in suppression between the serial and simultaneous test conditions, a $2 \times 2$ ANOVA, with inhibitor $(X$ or $\mathrm{Y}$ ) and test order (serial or simultaneous) as factors, was conducted on the suppression scores from these four test conditions. This ANOVA revealed no main effect of inhibitor $[F(1,44)=3.90, p>.05]$ or of test order $[F(1,44)<1, p>.40]$, but did reveal a significant interaction of the two factors $[F(1,44)=29.65, p<.001]$.

The reduced suppression (i.e., greater inhibition) observed in animals tested with the simultaneous $\mathrm{XC}$ and serial $\mathrm{Y} \stackrel{0}{\rightarrow} \mathrm{C}$ compounds supports the view that conditioned inhibition will be maximal when the time at which the US is expected, on the basis of transfer excitor, is the same as the time at which the omission of the US is expected, on the basis of the inhibitor. The hypothetical temporal maps presented in Figure 1 depict the expectancies generated by the inhibitors and the transfer excitors. As can be seen from this diagram, only the simultaneous $\mathrm{XC}$ and serial $\mathrm{Y} \stackrel{0}{\rightarrow} \mathrm{C}$ compounds create expectancies that are aligned in time. When the expectancies occur at inconsistent points in time (e.g., the simultaneous $\mathrm{YC}$ and serial $\mathrm{X} \stackrel{0}{\rightarrow} \mathrm{C}$ compounds), no inhibition was observed. One additional observation is that, with our procedure, a serial inhibitor was able to transfer its inhibitory control to an independently trained excitor, a finding that is inconsistent with those of Holland and his colleagues (Holland \& Lamarre, 1984; Lamarre \& Holland, 1987) but replicates the findings of Barnet and Miller (1996) and of Denniston et al. (1998).

\section{EXPERIMENT 2}

The purpose of Experiment 2 was to extend the results of Experiment 1 by manipulating the temporal relationships between the training excitors and the US and between the inhibitors and the transfer excitors at test, while holding constant the inhibitor-training excitor and the transfer excitor-US temporal relationships. The primary difference between this experiment and Experiment 1 was that, in the present experiment, the temporal relationship between the training excitors and the US was varied. Specifically, CS A continued to serve as a delay $\mathrm{CS}$ (i.e., $\mathrm{A} \stackrel{0}{\rightarrow}$ US), and a second CS (B) was introduced as a trace excitor, for which a 5-sec gap separated CS termination and US onset (i.e., $B \stackrel{5}{\rightarrow}$ US ). In addition, rather than varying the temporal relationship between the inhibitors and their transfer excitors (serial or simultaneous), this temporal relationship was fixed so that both inhibitors were trained simultaneously with one of the training excitors (i.e., $\mathrm{XA}-$ and $\mathrm{YB}-$ ). Transfer excitor training and testing were conducted as in Experiment 1.

On the basis of the putative expectancies generated as a result of inhibition and transfer excitor training, the superimposed temporal maps (see Figure 3) predict that maximal conditioned inhibition will be observed for the subjects tested with the simultaneous test with $\mathrm{XC}$, but not $\mathrm{YC}$, and with the serial test with $\mathrm{Y} \stackrel{0}{\rightarrow} \mathrm{C}$, but not $\mathrm{X} \stackrel{0}{\rightarrow} \mathrm{C}$. For example, inhibitor $\mathrm{X}$ activates an expectancy of nonreinforcement through its nonreinforced training history with excitor A (Figure 3, Panel 1). Because inhibitor X was simultaneously paired with excitor A (both $5 \mathrm{sec}$ in duration), and because excitor A was a delay CS with no gap between CS termination and US onset on its reinforced trials, the US would be expected to be omitted $5 \mathrm{sec}$ after onset of inhibitor X. During summation testing, only a simultaneous test of inhibitor $\mathrm{X}$ and transfer excitor $\mathrm{C}$ - which, through its serial pairings with the US, evokes an expectancy of the US $5 \mathrm{sec}$ following its onset-would result in simultaneous expectations of US omission and US presentation and, thus, maximal conditioned inhibition. If testing of $\mathrm{X}$ and $\mathrm{C}$ were conducted serially (see Figure 3, Panel 3), the expectancy of US omission would precede that of US presentation, resulting in less inhibition. A similar analysis of inhibitor $\mathrm{Y}$, which was trained with the trace excitor $B$, reveals that only a serial 


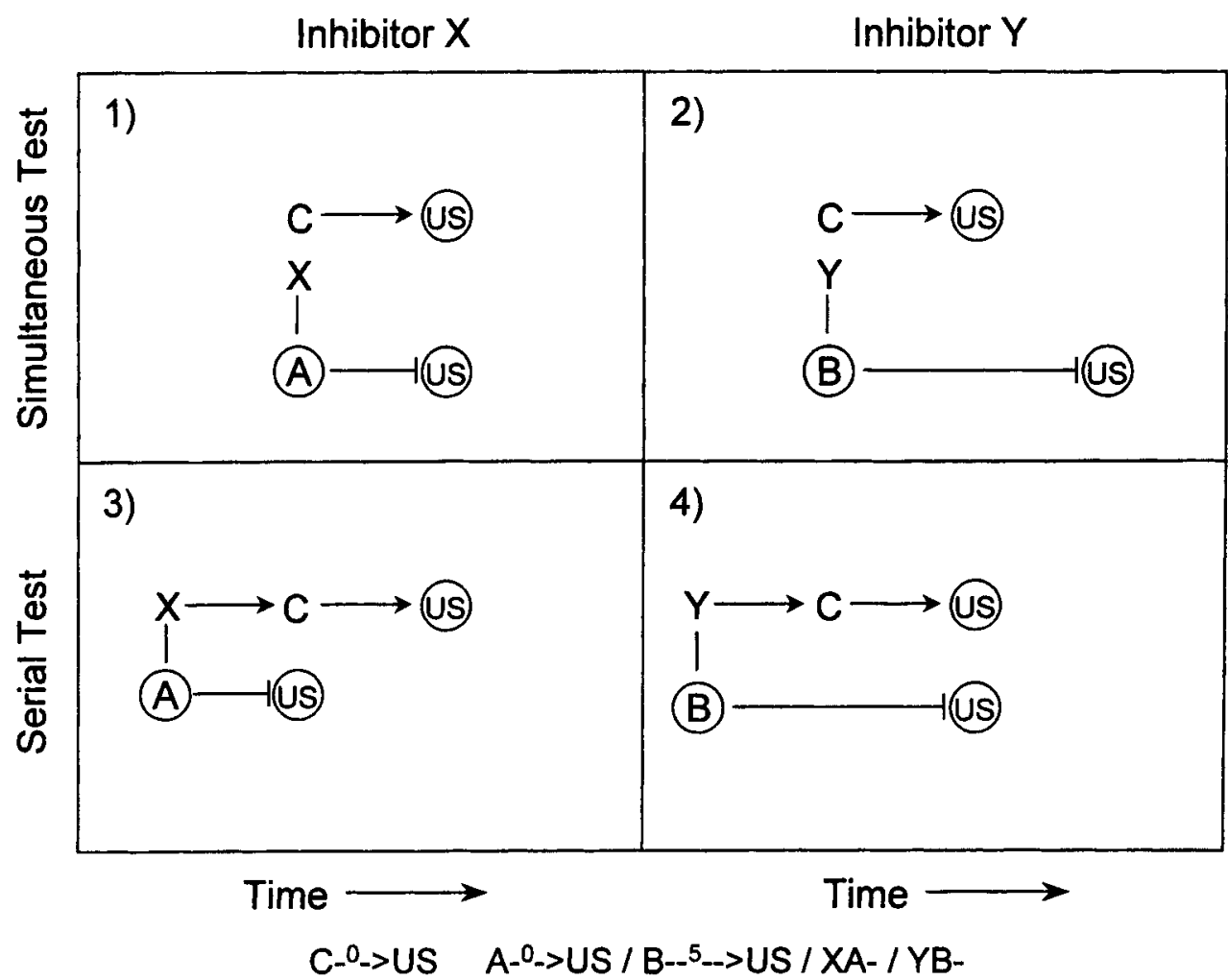

Figure 3. Hypothetical expectancies generated at test, as a result of conditioned inhibition training and transfer excitor training. Horizontal lines indicate a forward expectancy. Horizontal lines with an arrow represent an expected unconditioned stimulus (US); horizontal lines ending with a cross bar indicate that an otherwise expected US will be omitted. Vertical lines indicate a simultaneous expectancy. Maximal inhibition is hypothesized to occur when the time at which the US is expected is congruent with the time at which the US is signaled to be omitted. Panel 1: simultaneous XC test; Panel 2: simultaneous YC test; Panel 3: serial $X \rightarrow C$ test; Panel 4: serial $Y \rightarrow C$ test.

test with the transfer excitor should result in strong conditioned inhibition (see Figure 3, Panels 4 and 2).

\section{Method}

Subjects. The subjects were 30 male and 30 female naive SpragueDawley rats, counterbalanced for sex within groups. Body weights ranged from 250 to $410 \mathrm{~g}$ for males and from 180 to $240 \mathrm{~g}$ for females. Animal care and deprivation were the same as in Experiment 1.

Apparatus. The apparatus was the same as that in Experiment 1, except for the addition of a buzzer that could produce a "buzz" $8 \mathrm{~dB}$ (C) above the ambient background. In addition, the US was increased to a $0.5-\mathrm{sec}, 1.3-\mathrm{mA}$ footshock in order to increase conditioned responding to the transfer excitor in this and the subsequent study.

Procedure. Experiment 2 was similar in design to Experiment 1. Once again, the experiment was composed of three critical phases. The first phase consisted of conditioned inhibition training, in which two training excitors (A and B) were established as excitatory signals for the US. CS A was trained as a delay excitor (i.e., $A \stackrel{0}{\rightarrow}$ US), whereas CS B was trained as a trace excitor (i.e., $\mathrm{B} \stackrel{5}{\rightarrow}$ US). As in Experiment 1, two inhibitors were trained, but now both were established as simultaneous inhibitors with their respective training excitors $\mathrm{A}$ and $\mathrm{B}$ (i.e., $\mathrm{XA}-$ and $\mathrm{YB}-$-). Transfer excitor training was the same as that in Experiment 1 (i.e., $\mathrm{C} \rightarrow$ US).

Acclimation. Acclimation to the three contexts was the same as that in Experiment 1.

Conditioned inhibition training. Conditioned inhibition training was conducted over 24 sessions. Days 4-24 and 31-33 in Con- text CI Train. During these daily 80-min sessions, the subjects received six $\mathrm{A} \stackrel{0}{\rightarrow} \mathrm{US}$, six B $\stackrel{5}{\rightarrow} \mathrm{US}$, six XA-, and six YA-trials per session. Training excitors $A$ and $B$ were the flashing light and the buzz, counterbalanced within test conditions, and $X$ and $Y$ were the tone and white noise, counterbalanced within test conditions. All the sessions began with a reinforced trial; the remaining reinforced and nonreinforced trials were pseudorandomly distributed within the session. The mean intertrial interval (CS onset to CS onset) was $3 \mathrm{~min}$, with a range of $1.5-4.5 \mathrm{~min}$. Two different training schedules, which differed by trial order, were alternated daily, using an A, B, B, A pattern.

Transfer excitor training. Transfer excitor training (Days 25-30) was the same as that in Experiment 1.

Reacclimation. Reacclimation (Days 34-36) to Context Test was the same as that in Experiment 1, except that an additional session of reacclimation was given because several animals initially showed a reluctance to drink in Context Test.

Testing. Testing (Day 37) was conducted in the same manner as in Experiment 1. To review, the subjects were divided into five test conditions $(n=12)$ and were tested with either the transfer excitor (C) alone, simultaneous inhibitor-transfer excitor compounds (XC or $\mathrm{YC}$ ), or serial inhibitor-transfer excitor compounds $(\mathrm{X} \rightarrow \mathrm{C}$ or $\mathrm{Y} \stackrel{0}{\rightarrow} \mathrm{C})$.

Three animals, 1 from each of Test Conditions $\mathrm{C}, \mathrm{XC}$, and $\mathrm{X} \stackrel{0}{\rightarrow}$ $\mathrm{C}$, required more than $60 \mathrm{sec}$ to complete the initial 5 cumulative sec of drinking prior to the presentation of the test stimuli on Day 37, thus showing a reluctance to drink in Context Test. The data from these animals were discarded. Additionally, 1 animal from 
Test Condition $\mathrm{XC}$ died before the completion of the experiment. This left $n=11$ for the subjects tested with $\mathrm{C}, 10$ for $\mathrm{XC}, 12$ for $\mathrm{YC}, 11$ for $\mathrm{X} \stackrel{0}{\rightarrow} \mathrm{C}$, and 12 for $\mathrm{Y} \stackrel{0}{\rightarrow} \mathrm{C}$.

\section{Results and Discussion}

The results of Experiment 2 indicated that the subjects tested with the simultaneous $\mathrm{XC}$ and serial $\mathrm{Y} \stackrel{0}{\rightarrow} \mathrm{C}$ test compounds displayed less conditioned suppression (i.e., behavior indicative of conditioned inhibition) than did the subjects tested with the transfer excitor alone, the simultaneous $\mathrm{YC}$ compound, or the serial $\mathrm{X} \stackrel{0}{\rightarrow} \mathrm{C}$ compound. As in Experiment 1, conditioned inhibition was greatest when the no-US expectation evoked by an inhibitor corresponded temporally with the US expectation evoked by a transfer excitor. Figure 4 depicts the mean time to complete the 5 cumulative sec of drinking in the presence of the test stimuli.

The above findings were confirmed with the following statistical analyses. As in Experiment 1, a one-way ANOVA, with test stimulus as the factor, was conducted on the suppression scores. The ANOVA revealed a main effect of test stimulus $[F(4,51)=12.71, p<.001]$. Planned comparisons using the error term from the ANOVA were conducted on the suppression scores of the test conditions. Comparisons of the levels of responding between subjects tested with the transfer excitor alone and those tested with the simultaneous compounds $\mathrm{XC}$ and $\mathrm{YC}$ revealed less conditioned suppression in Test Condition $\mathrm{XC}$ than in Test Condition $C[F(1,51)=17.72, p<.001]$ and no dif- ference in suppression between Test Conditions YC and $\mathrm{C}[F(1,51)=1.12, p>.20]$. Contrasts of differences in suppression between subjects tested with the transfer excitor alone and those tested with the serial compounds $\mathrm{X} \stackrel{0}{\rightarrow} \mathrm{C}$ and $\mathrm{Y} \stackrel{0}{\rightarrow} \mathrm{C}$ revealed no difference in suppression between the subjects tested with $\mathrm{C}$ alone and $\mathrm{X} \stackrel{0}{\rightarrow} \mathrm{C}$ $[F(1,51)<1, p>.70]$ and a significant reduction in suppression in the subjects tested with $\mathrm{Y} \rightarrow \mathrm{C}$, relative to those tested with $\mathrm{C}$ alone $[F(1,51)=30.93, p<.001]$. Further comparisons contrasted the differences in responding between the subjects tested with the two simultaneous compounds and between the subjects tested with the two serial compounds. These comparisons found suppression to $\mathrm{Y} \stackrel{0}{\rightarrow} \mathrm{C}$ to be significantly less than that observed to $\mathrm{X} \stackrel{0}{\rightarrow} \mathrm{C}[F(1,51)=27.45, p<.001]$ and suppression to $\mathrm{XC}$ to be reliably less than that to $\mathrm{YC}[F(1,51)=10.66$, $p<.01]$. To further explore the differences between the simultaneous and the serial tests with inhibitors $\mathrm{X}$ and $\mathrm{Y}$, a $2 \times 2$ ANOVA, with inhibitor ( $\mathrm{X}$ or $\mathrm{Y}$ ) and test order (serial or simultaneous) as factors, was conducted on the suppression scores from these four test conditions. The ANOVA revealed no main effect of inhibitor $[F(1,41)=$ $1.62, p>.20]$ or of test order $[F(1,41)<1, p>.70]$, but did reveal a significant interaction of the two factors $[F(1,41)=33.39, p<.001]$.

The results from Experiment 2 support an interpretation of conditioned inhibition in terms of the temporal coding hypothesis, in that the greatest conditioned inhibition was observed when the time at which the inhibitor

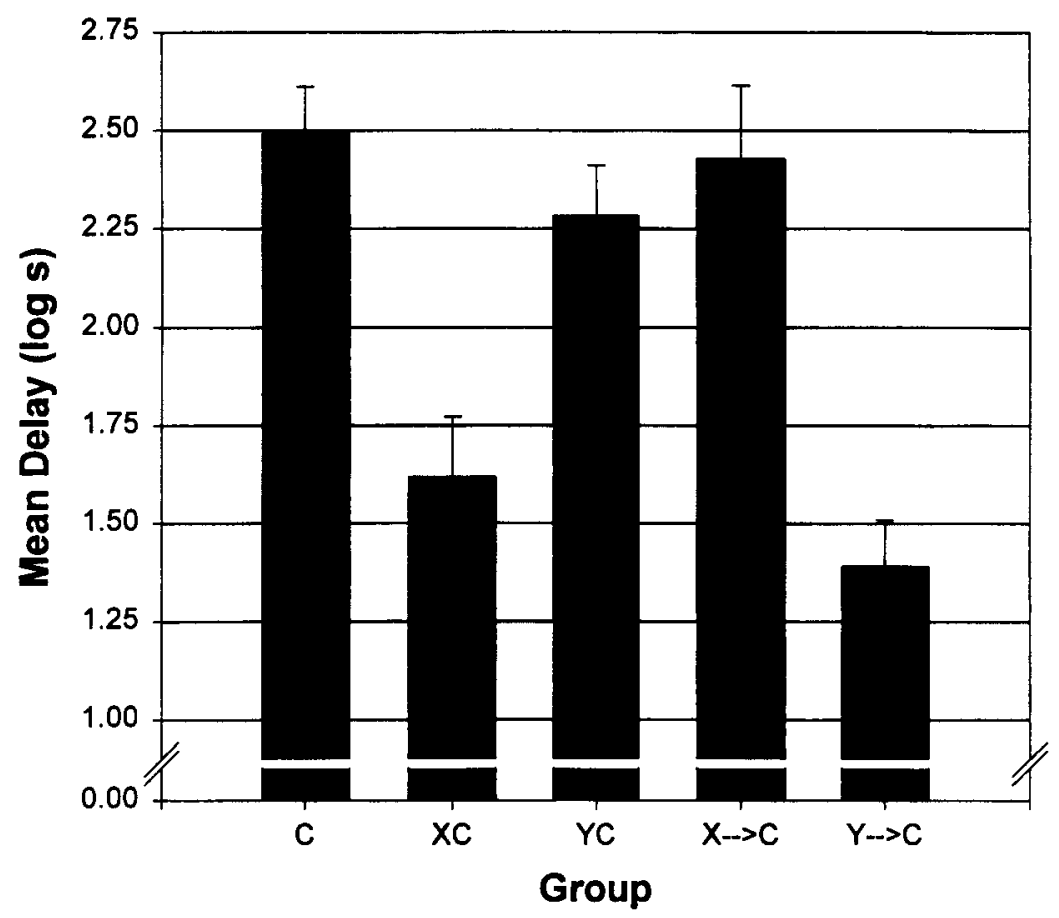

Figure 4. Mean times to complete 5 cumulative sec of drinking in the presence of the test stimuli in Experiment 2. Greater scores indicate less conditioned inhibition. Bars represent standard error of means. 
signaled the absence of the US was the same as the time at which the transfer excitor signaled presentation of the US. This pattern of results was independent of whether testing occurred serially or simultaneously. Rather, the observed pattern of results was determined by the temporal relationships between the inhibitors and their training excitors, between the training excitors and the US, and between the transfer excitor and the US. At test, any temporal arrangement of the inhibitor and the transfer excitor that evoked a no-US representation and a US representation, respectively, at the same time resulted in negative summation that was indicative of conditioned inhibition. This pattern of results can be seen in the subjects tested with the simultaneous $\mathrm{XC}$ stimulus and with the serial $\mathrm{Y} \rightarrow \mathrm{C}$ stimulus. In addition, the inhibitory strength of the conditioned inhibitor did not appear to depend on the strength of the conditioned response evoked by the training excitor. That is, it might be expected that a simultaneous conditioned inhibitor trained with a trace excitor (inhibitor $Y$ ) would be less effective as an inhibitor than would a simultaneous inhibitor established with a delay excitor (inhibitor $\mathrm{X}$ ), because the conditioned response evoked by a trace excitor is usually smaller than that observed with a delay excitor. Such a prediction is not supported by our finding that the strength of conditioned inhibition observed in the serial $\mathrm{Y} \stackrel{0}{\rightarrow} \mathrm{C}$ test tended to be greater than that observed in the simultaneous XC test (see Figure 4).

\section{EXPERIMENT 3}

Experiment 3 sought to extend the findings of Experiments 1 and 2 by manipulating the temporal relationships between the transfer excitor and the US and between the inhibitor and the transfer excitor at test, while holding constant the training excitor-US and inhibitor-training excitor temporal relationships. In this experiment, we established two transfer excitors with different temporal relationships with the US (trace or delay), for the purpose of testing. Transfer excitor $\mathrm{C}$ was established as a delay $\mathrm{CS}(\mathrm{C} \rightarrow \mathrm{US})$, and transfer excitor $\mathrm{D}$ was established as a trace $\mathrm{CS}(\mathrm{D} \stackrel{5}{\rightarrow}$ US). Because the training excitor-US and inhibitor-training excitor temporal relationships were not varied in this study, we used only one training excitor and one inhibitor during conditioned inhibition training. Training excitor $\mathrm{A}$ was trained as a delay CS (i.e., $\mathrm{A} \stackrel{0}{\rightarrow} \mathrm{US}$ ), and conditioned inhibitor $\mathrm{X}$ was established as a serial signal for US omission (i.e., $\mathrm{X} \rightarrow \mathrm{0} \rightarrow \mathrm{A}$ ). Testing was similar to that in Experiments 1 and 2, except that the potential of inhibitor $\mathrm{X}$ to transfer its inhibitory control was tested with both transfer excitors (C and D), using both serial and simultaneous tests.

On the basis of prior studies of transfer of inhibition (Holland \& Lamarre, 1984; Lamarre \& Holland, 1987), it could be hypothesized that the use of a serial inhibitor would result in reduced transfer of inhibitory control when testing occurs with independently trained excitors. Alternatively, the temporal coding hypothesis predicts that any summation test in which the inhibitor signals US omission at the same temporal location as that at which the transfer excitor signals the forthcoming US would result in conditioned inhibition. Applied to the present experiment, the temporal coding hypothesis predicts that conditioned inhibition should be greatest when the subjects are tested with a simultaneous XD transfer test and with a serial $X \stackrel{0}{\rightarrow} C$ transfer test. These predictions are illustrated in Figure 5, which presents the hypothetical temporal maps generated during conditioned inhibition and transfer excitor training. For example, the simultaneous XD summation test (see Figure 5, Panel 2) should result in maximal conditioned inhibition because inhibitor $\mathrm{X}$, through its serial pairings with the training excitor $\mathrm{A}$ (which was serially paired with the US), signals omission of the US $10 \mathrm{sec}$ following onset of X, and transfer excitor $\mathrm{D}$, which was trained as a trace excitor, signals US presentation $10 \mathrm{sec}$ following its onset. However, the use of a serial test for X and D (see Figure 5, Panel 4), which in effect shifts the no-US expectancy to a temporal location that is $5 \mathrm{sec}$ prior to the US expectation provided by the transfer excitor, should result in less conditioned inhibition.

\section{Method}

Subjects. The subjects were 30 male and 30 female naive SpragueDawley rats, assigned to groups counterbalanced for sex. Body weights ranged from 232 to $356 \mathrm{~g}$ for males and from 184 to $255 \mathrm{~g}$ for females. Animal care and deprivation were the same as in Experiments 1 and 2 .

Apparatus. The apparatus was the same as that in Experiments 1 and 2 , except for the addition of a low-frequency complex tone ( 300 and $320 \mathrm{~Hz}$ ), which was presented $8 \mathrm{~dB}(\mathrm{C})$ above background. The high-frequency tone and buzz stimuli were not used in this experiment.

Procedure. Experiment 3 was similar in design to Experiments 1 and 2. Again, all the subjects received three phases of treatment. The first phase was conditioned inhibition training, in which a single training excitor (A) was established as an excitatory delay CS (i.e., $A \stackrel{0}{\rightarrow}$ US). Additionally, a single inhibitor (X) was established as a serial inhibitor with training excitor $A$ (i.e., $X \stackrel{0}{\rightarrow} A-$ ). Transfer excitor training consisted of establishing two CSs (C and D) as excitatory signals for the US. Transfer excitor $\mathrm{C}$ was trained as a delay $\mathrm{CS}$, with $\mathrm{CS}$ termination coinciding with US onset (i.e., $\mathrm{C} \rightarrow$ US), whereas transfer excitor D was trained as a trace CS, with a 5 -sec gap between CS termination and US onset (i.e., $D^{\stackrel{5}{\rightarrow}}$ US). The third phase of the experiment was testing, which was conducted in a manner similar to that in Experiments $l$ and 2, except that the inhibitory ability of $X$ was assessed with transfer excitors $C$ and $D$, using both serial and simultaneous tests.

Acclimation. Acclimation to the three contexts was the same as that in Experiments 1 and 2.

Conditioned inhibition training. Conditioned inhibition training was conducted over 16 sessions, Days 4-16 and 25-27 in Context CI Train. During these daily 60-min sessions, the subjects received nine $\mathrm{A} \stackrel{0}{\rightarrow} \mathrm{US}$ and nine $\mathrm{X} \stackrel{0}{\rightarrow} \mathrm{A}-$ trials per session. CS $\mathrm{A}$ was the flashing light, and inhibitor $X$ was the white noise. All the sessions began with a reinforced trial; the remaining reinforced and nonreinforced trials were pseudorandomly distributed within the session. The mean intertrial interval (CS onset to CS onset) was 


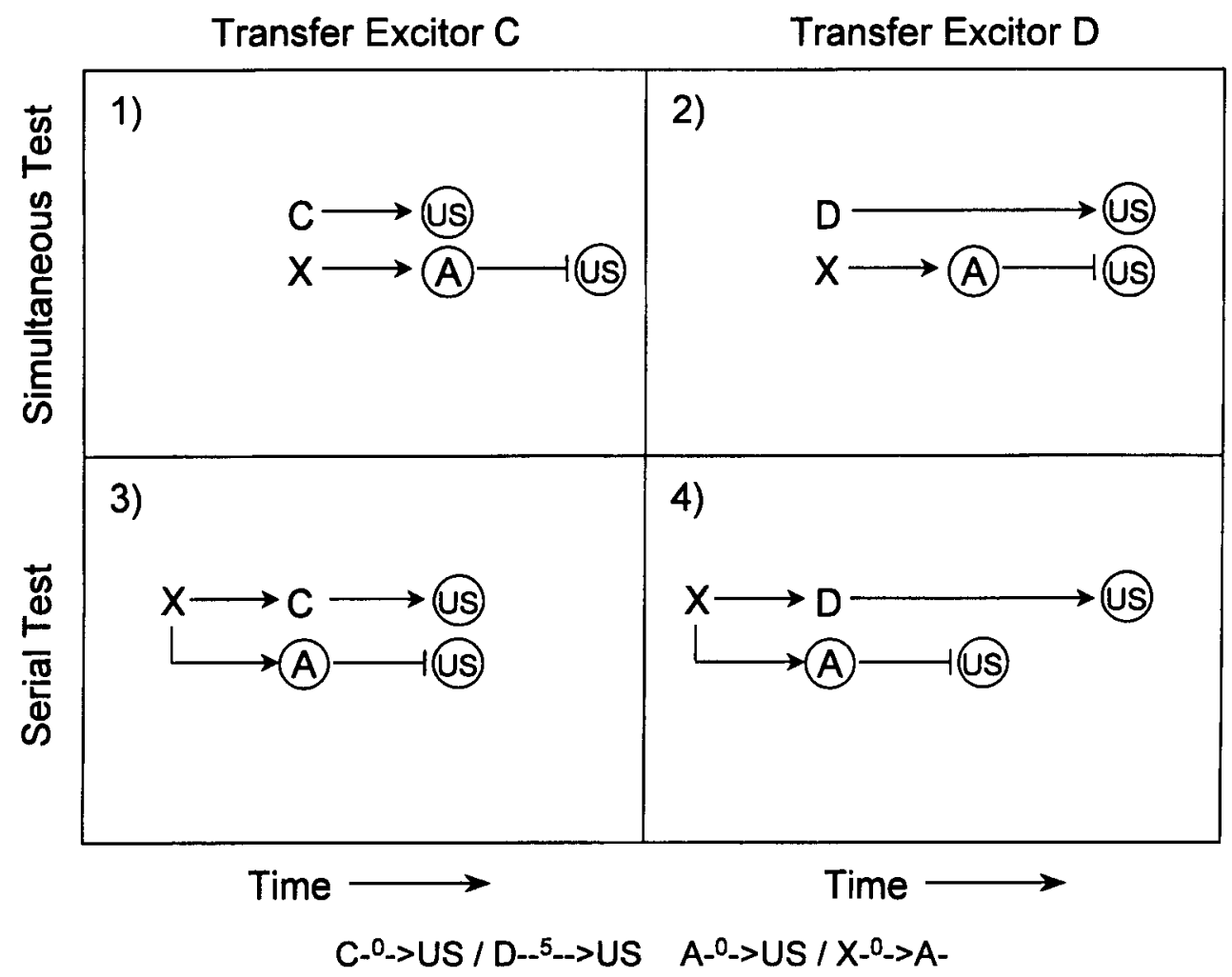

Figure 5. Hypothetical expectancies generated at test, as a result of conditioned inhibition training and transfer excitor training. Horizontal lines indicate a forward expectancy. Horizontal lines with an arrow represent an expected unconditioned stimulus (US); horizontal lines ending with a cross bar indicate that an otherwise expected US will be omitted. Vertical lines indicate a simultaneous expectancy. Maximal inhibition is hypothesized to occur when the time at which the US is expected is congruent with the time at which the US is signaled to be omitted. Panel 1: simultaneous XC test; Panel 2: simultaneous XD test; Panel 3: serial $X \rightarrow C$ test; Panel 4: serial $X \rightarrow D$ test.

$3 \mathrm{~min}$, with a range of $1.5-4.5 \mathrm{~min}$. Three different training schedules, which differed by trial order, were alternated, using an A, B, C, C, B, A pattern across days.

Transfer excitor training. Transfer excitor training (Days 17-24) was similar to that in Experiments 1 and 2, except that an additional transfer excitor D was established. Transfer excitor training consisted of three reinforced $\mathrm{C} \stackrel{0}{\rightarrow}$ US, three nonreinforced $\mathrm{C}-$, three reinforced $\mathrm{D} \stackrel{5}{\rightarrow} \mathrm{US}$, and three nonreinforced $\mathrm{D}-$ trials per day, during each of the eight daily 60 -min sessions in Context Transfer Train. The click train and low-frequency tone served as training excitors $\mathrm{C}$ and $\mathrm{D}$, counterbalanced within each test condition. Reinforced and nonreinforced trials were pseudorandomly distributed within each session and were separated by a 4.5-min mean intertrial interval that ranged from 1.5 to $7.5 \mathrm{~min}$. All the transfer excitor training sessions began with a reinforced trial. Two different training schedules, which differed by trial order, were alternated, using an A, B, B, A pattern across days.

Reacclimation. Reacclimation (Days 28-30) to Context Test was the same as that in Experiment 2.

Testing. Testing (Day 31 ) was conducted in the same manner as in Experiment 1, except that, in the present experiment, testing was conducted with two different transfer excitors and only one inhibitor. To summarize, the subjects were divided into six test conditions $(n=10)$, counterbalanced for sex, and were tested with either the transfer excitor (C or D) alone, a simultaneous inhibitor-transfer excitor compound (XC or XD), or a serial inhibitor-transfer excitor compound $(\mathrm{X} \stackrel{0}{\rightarrow} \mathrm{C}$ or $\mathrm{X} \stackrel{0}{\rightarrow} \mathrm{D})$.
Two animals, 1 each from Test Conditions $\mathrm{C}$ and $\mathrm{X} \stackrel{0}{\rightarrow} \mathrm{D}$, required more than $60 \mathrm{sec}$ to complete the initial 5 cumulative sec of drinking prior to the presentation of the test stimuli, thus showing a reluctance to drink in Context Test. The data from these animals were discarded. Additionally, 2 animals, 1 each from Test Conditions $\mathrm{C}$ and $\mathrm{X} \rightarrow \mathrm{C}$, died before the completion of the experiment. This left $n=8$ for the subjects tested with $\mathrm{C}, 10$ for $\mathrm{XC}, 10$ for $\mathrm{XD}, 9$ for $\mathrm{X} \stackrel{0}{\rightarrow} \mathrm{C}$, and 9 for $\mathrm{X} \stackrel{0}{\rightarrow} \mathrm{D}$.

\section{Results and Discussion}

The primary result from Experiment 3 was that there was less conditioned responding by the subjects tested with $\mathrm{X} \stackrel{0}{\rightarrow} \mathrm{C}$ and $\mathrm{XD}$ than by the subjects tested with the respective transfer excitors alone. Additionally, no reduction in responding was observed in the subjects tested with $\mathrm{XC}$ and $\mathrm{X} \stackrel{0}{\rightarrow} \mathrm{D}$, relative to those tested with the respective transfer excitors alone. This pattern of results supports the predictions derived from the temporal coding hypothesis, in that inhibition was greatest when the inhibitor signaled omission of the US at the same temporal location as that at which the transfer excitor signaled presentation of the US. Figure 6 depicts the mean time to complete the 5 cumulative sec of drinking in the presence of the test stimuli. 


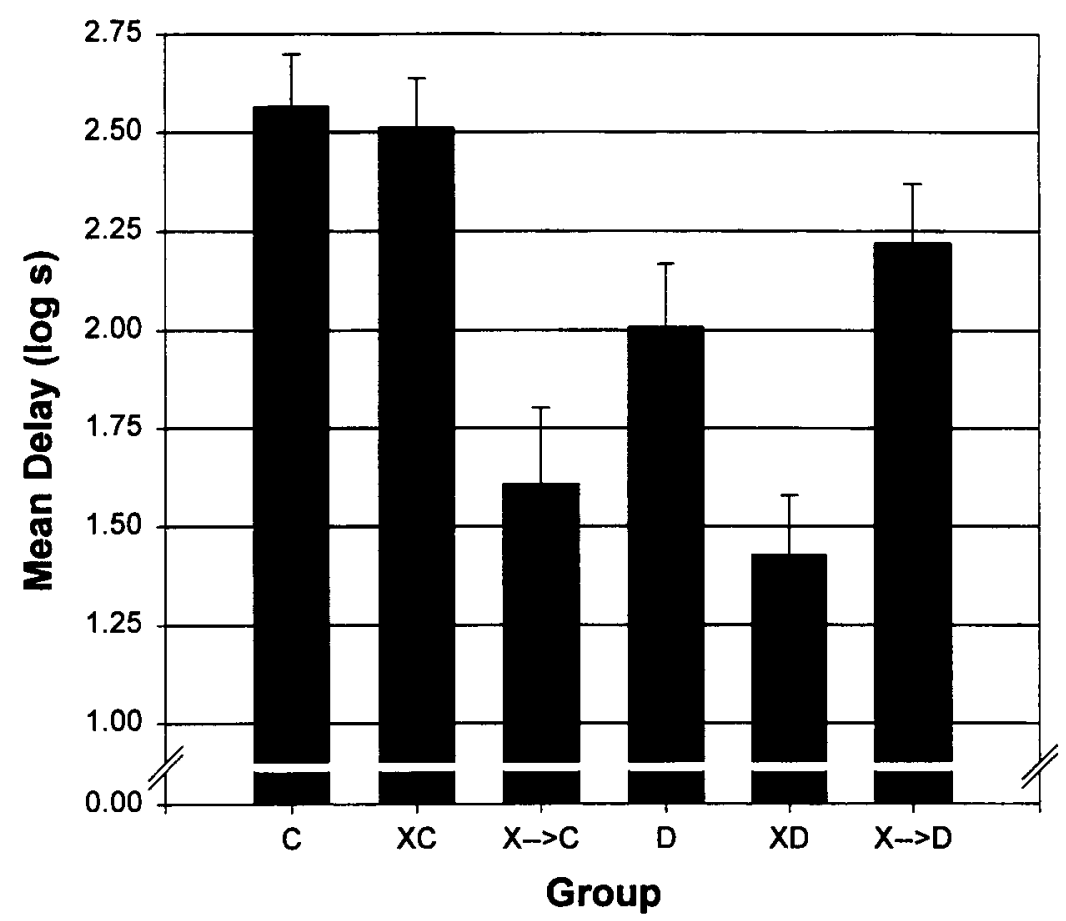

Figure 6. Mean times to complete 5 cumulative sec of drinking in the presence of the test stimuli in Experiment 3. Greater scores indicate less conditioned inhibition. Bars represent standard error of means.

The following statistical analyses supported the above conclusions. A one-way ANOVA, with test stimulus as the factor, was conducted on the suppression scores. This ANOVA revealed a main effect of test stimulus $[F(5,50)=$ $9.15, p<.001]$. As in the previous experiments, planned comparisons using the error term from the one-way ANOVA were conducted on the suppression scores of the test conditions. Comparisons of suppression scores for the subjects tested with transfer excitor $C$ revealed less suppression on $\mathrm{X} \rightarrow \mathrm{C}$ than on $\mathrm{C}$ alone $[F(1,50)=17.47$, $p<.001]$, whereas there was no reduction in suppression by the subjects tested with $\mathrm{XC}$, relative to $\mathrm{C}[F(1,50)<1$, $p>.80]$. In addition, the difference in suppression between Test Conditions $\mathrm{X} \stackrel{0}{\rightarrow} \mathrm{C}$ and $\mathrm{XC}$ was significant $[F(1,50)=$ $17.43, p<.001]$. Comparisons of suppression scores for the subjects tested with transfer excitor $D$ revealed that reduced suppression in the subjects tested with XD, relative to $\mathrm{D}$, was significant $[F(1,50)=7.59, p<.01]$, and that there was no reduction in responding in the animals tested with $\mathrm{X} \stackrel{0}{\rightarrow} \mathrm{D}$, relative to $\mathrm{D}$ alone $[F(1,50)<1, p>$ .30]. Furthermore, the difference in conditioned suppression between $\mathrm{XD}$ and $\mathrm{X} \stackrel{0}{\rightarrow} \mathrm{D}$ was also significant $[F(1,50)$ $=13.41, p<.001]$. To better appreciate the interaction between the transfer excitor-US temporal interval and the inhibitor-transfer excitor temporal relationship at test, a $2 \times 2$ ANOVA, with transfer excitor (C or D) and test order (serial or simultaneous) as factors, was conducted on the suppression scores from Test Conditions $\mathrm{XC}, \mathrm{X} \stackrel{0}{\rightarrow} \mathrm{C}$, $\mathrm{XD}$, and $\mathrm{X} \stackrel{0}{\rightarrow} \mathrm{D}$. The ANOVA revealed no main effect of transfer excitor $[F(1,34)=2.30, p>.10]$ or of test order
$[F(1,34)<1, p>.70]$, but did reveal a significant interaction of the two factors $[F(1,34)=29.77, p<.001]$.

The results from this study are fully consistent with the temporal coding hypothesis' predictions of when conditioned inhibition will be observed in summation tests. Inhibition was observed only when the no-US expectation evoked by the conditioned inhibitor was temporally aligned with the US expectation evoked by the transfer excitor. Any test in which the no-US expectation provided by the inhibitor occurred earlier (e.g., the $\mathrm{X} \stackrel{0}{\rightarrow} \mathrm{D}$ serial test) or later (e.g., the XC simultaneous test) than the US expectation provided by the transfer excitor failed to produce conditioned inhibition. Furthermore, this experiment provides yet another demonstration of transfer of conditioned inhibition by a serial inhibitor, with procedures that differed from those in the present Experiment 1 and from those in the Barnet and Miller (1996) and Denniston et al. (1998) experiments.

\section{GENERAL DISCUSSION}

In the present series of experiments, the role of temporal coding in the transfer of serial and simultaneous conditioned inhibitors was investigated, using both simultaneous and serial summation tests with independently trained excitors. Each experiment varied the temporal relationship between the inhibitor and the transfer excitor at test and one of the three remaining temporal relationships: (1) the temporal relationship between the inhibitor and the training excitor, in Experiment 1; (2) the tempo- 
ral relationship between the training excitor and the US, in Experiment 2; and (3) the temporal relationship between the transfer excitor and the US, in Experiment 3. The results from each experiment demonstrated that the temporal arrangement of any one of these variables was not directly responsible for the occurrence of behavior indicative of inhibition. Rather, what critically determined when conditioned inhibition would be observed was the simultaneous activation of a no-US representation evoked by the conditioned inhibitor and a US representation evoked by the transfer excitor. That is, whether the inhibitor was trained as a serial or simultaneous signal for US omission did not determine whether transfer would occur. Instead, the temporal arrangements between the inhibitor and the training excitor and between the training excitor and the US, conjointly established the inhibitor as a signal for US omission at a specific temporal location.

These results, although extending and replicating the findings of Barnet and Miller (1996) and of Denniston et al. (1998), produce a discrepancy in the literature. Holland and his colleagues (Holland, 1984, 1989; Holland \& Lamarre, 1984; Lamarre \& Holland, 1987) have consistently reported that serial and simultaneous featurenegative discrimination training result in two different types of negative features. The serial negative feature generally fails to modulate responding to independently trained excitors that were consistently or partially reinforced, as well as trained, extinguished, and then retrained, but will modulate responding to excitors that were trained as targets in other feature-negative discriminations (Holland \& Lamarre, 1989; Lamarre \& Holland, 1987). However, following simultaneous feature-negative training, simultaneous features readily transfer to independently trained excitors. Furthermore, Holland (1984) has reported that, following feature-negative discrimination training, reinforcement of a simultaneous, but not a serial, feature impaired transfer of inhibitory control. In contrast to these studies, the present series of experiments, as well as the experiments by Barnet and Miller and Denniston et al., has found that both serial and simultaneous inhibitors readily transfer their inhibitory control, provided that the no-US expectancy evoked by the inhibitor coincides temporally with the expectancy for reinforcement provided by the transfer excitor.

Although the present series of experiments rules out temporal relationships at test as the source of the discrepancy between the present findings and those of Holland and his colleagues, many other procedural differences exist. One such difference is the method of testing. In Holland's experiments, the test stimuli were presented for the same duration as in training, whereas, in the present series of experiments, as well as in the Barnet and Miller (1996) and Denniston et al. (1998) series, a flooding measure was used. In addition, many of Holland's studies have used conditioned barpress suppression (see, e.g., Holland, 1984; Holland \& Lamarre, 1984; Lamarre \& Holland, 1987), whereas the studies by Miller and col- leagues used conditioned lick suppression. Such differences raise the possibility that the present findings might be paradigm specific. However, some prior studies from our laboratory investigating temporal coding have used conditioned barpress suppression (see, e.g., Savastano, Yin, Barnet, \& Miller, 1998), suggesting that temporal coding effects are not paradigm specific. Furthermore, the use of longer CSs during testing than in training raises the question of why the animals continued to suppress drinking long after the US was expected to have been presented. That animals continue to suppress drinking long after the US was expected to be presented suggests that conditioned fear might be mediated by slow-acting factors that continue long after their onset (e.g., hormonal release). Thus, there are grounds to believe that our effects are neither paradigm specific nor problematic for a temporal coding account that posits that animals are capable of learning precise time relationships.

Although the source of the discrepancy between the findings of Holland and his colleagues and ours remains unclear, Holland, Hamlin, and Parsons (1997) have recently reported the importance of temporal variables in occasion setting. In their studies, it was found that, following serial feature-positive discrimination training, the ability of the feature to modulate responding to a target varied as a function of the feature-target CS temporal interval used during discrimination training. That is, when the feature-target CS temporal interval of training was maintained during testing, modulation by the target was greatest; when the temporal intervals were varied during testing, so that the feature-target CS temporal interval was increased or decreased, modulation decreased as a function of the discrepancy between the training and testing temporal intervals. These results are easily accommodated by a temporal coding hypothesis account, which predicts that modulation will be greatest when the feature-target CS temporal interval preserves simultaneous temporal expectancies of reinforcement and nonreinforcement and will decrease as the temporal expectancies of reinforcement and nonreinforcement provided by the feature and target CS at test diverge.

According to the temporal coding hypothesis, behavior indicative of conditioned inhibition results from an inhibitor-no-US expectancy that is established during conditioned inhibition training, so that the no-US expectation is placed at the moment that the US is expected on the basis of some other cue (i.e., a transfer excitor). However, how such an inhibitor-no-US expectancy is represented in memory and then transformed into behavior has not been discussed. One possible theoretical account of conditioned inhibition is provided by the comparator hypothesis (Miller \& Matzel, 1988; Miller \& Schachtman, 1985). The comparator hypothesis is a response rule for the expression of Pavlovian associations. It states that conditioned responding is determined by a comparison that occurs at the time of testing between the US representation activated by the target CS and the US representation activated by the target CS's comparator stimuli 
(i.e., other salient stimuli that were present during training with the target stimulus). Moreover, the representations of the comparator stimuli themselves are activated at test through their association with the target CS. Consequently, the activation sequence for the latter US representation in this comparison is target CS $\rightarrow$ comparator stimulus $\rightarrow$ US. As the strength of the target CS-US association increases, relative to the product of the CScomparator stimulus association and the comparator stimulus-US association, excitatory conditioned responding to the CS should increase, and behavior indicative of inhibition should decrease. Conversely, as the strength of the target CS-US association decreases, relative to the aforementioned product, excitatory responding to the CS should decrease, and behavior indicative of inhibition should increase. Thus, according to the comparator hypothesis, all associations are excitatory, and conditioned responding is determined by the comparison between the US representation activated by the target CS and the US representation activated by the comparator stimuli. Such a view of inhibition stands in contrast to traditional associative acquisition models of Pavlovian conditioning (see, e.g., Rescorla \& Wagner, 1972), which posit that conditioned inhibitors possess negative associative value with respect to the US. Instead, the comparator hypothesis posits that conditioned inhibitors possess weak excitatory associations to the US. This weak excitatory association with the US is most likely the result of second-order excitation mediated by the training excitor. (For example, Williams, Travis, \& Overmier [1986] found that presentations of the inhibitor in the absence of the training excitor enhanced the inhibitory potential of the inhibitor, presumably by extinguishing the inhibitor's second-order excitatory potential.)

The comparator hypothesis accounts for the negative summation that is frequently observed following Pavlovian conditioned inhibition training by assuming that responding at test reflects the sum of the output of the comparator process for each element presented in the test compound (provided the basic comparison is subtractive). That is, the positive response potential of the transfer excitor is reduced by the negative response potential of the conditioned inhibitor. Such a summation rule can readily explain both positive and negative summation effects (see Williams, Overmier, \& LoLordo, 1992, for a discussion of averaging and summation rules for the comparator hypothesis). Consistent with a comparator hypothesis view of conditioned inhibition, posttraining extinction of the excitor used during inhibition training has been observed to attenuate the inhibitory potential of a CS (see, e.g., Hallam, Matzel, Sloat, \& Miller, 1990; Lysle \& Fowler, 1985). Thus, the inhibitory potential of the conditioned inhibitor depends, in part, on the associative status of its training excitor at the time of testing. To accommodate the present findings that the specific temporal expectancy for US omission influences whether conditioned inhibition will be observed, we are currently suggesting that this temporal expectancy is determined collectively by the temporal relationships between the inhibitor and its comparator stimulus (the training excitor) and between the comparator stimulus and the US. At test, the potential of the inhibitor to attenuate conditioned responding to a transfer excitor during a summation test will depend, in part, on the temporal expectancy for the US provided by its comparator stimulus.

Conjoint application of both the temporal coding hypothesis and the comparator hypothesis to the present experiment provides a more complete account of conditioned inhibition than does either hypothesis alone. Whereas the comparator hypothesis maintains that an inhibitor possesses weak positive excitatory strength, of equal importance is the temporal signal value provided by the inhibitor. That is, as a result of conditioned inhibition training, the inhibitor becomes a signal for this weak US at a specific moment in time. Whereas the weakUS association results from an inhibitor-US association, the temporal expectancy for this weak US is determined by both the inhibitor-training excitor temporal relationship and the training excitor-US temporal relationship. Thus, we are proposing that the training excitor serves as the primary comparator stimulus for the inhibitor, in the manner posited by the comparator hypothesis, and additionally acts as a determinant of the temporal location of the associated weak-US expectation. (In this framework, our previous references to "no-US representations" might better read "weak-US representations.") If the comparator stimulus (training excitor)-US temporal relationship is a factor in determining the inhibitor-weak-US temporal relationship, then a change in the comparator stimulusUS temporal relationship after inhibitory training was completed should result in retrospective updating of the inhibitor-weak-US temporal relationship. This expectation is entirely consistent with the present observations.

In summary, this series of studies demonstrates the importance of the representation of temporal relationships in studies of associative learning. It is becoming clear that traditional models of associative learning that treat temporal contiguity merely as a catalyst for the formation of associations are no longer viable. Whether an integration of the temporal coding hypothesis and the comparator hypothesis will provide a better explanation of the available data, as well as new directions of research, remains to be determined.

\section{REFERENCES}

Barnet, R. C., Arnold, H. M., \& Miller, R. R. (1991). Simultaneous conditioning demonstrated in second-order conditioning: Evidence for similar associative structure in forward and simultaneous conditioning. Learning \& Motivation, 22, 253-268.

Barnet, R. C., Cole, R. P., \& Miller, R. R. (1997). Temporal integration in second-order conditioning and sensory preconditioning. Animal Learning \& Behavior, 25, 221-233.

Barnet, R. C., Grahame, N. J., \& Miller, R. R. (1993). Temporal encoding as a determinant of blocking. Journal of Experimental Psychology: Animal Behavior Processes, 19, 327-341.

BARnet, R. C., \& Miller, R. R. (1996). Temporal encoding as a determinant of inhibitory control. Learning \& Motivation, 27, 73-91

Blaisdel.l, A. P., Denniston, J. C., \& Miller, R. R. (1998). Temporal encoding as a determinant of overshadowing. Journal of Experimental Psychology: Animal Behavior Processes, 24, 72-83. 
Church, R. M. (1984). Properties of the internal clock. In J. Gibbon \& L. Allen (Eds.), Timing and time perception (Annals of the New York Academy of Sciences, Vol. 423, pp. 566-582). New York: New York Academy of Sciences.

Cole, R. P., Barnet, R. P., \& Miller, R. R. (1995). Temporal encoding in trace conditioning. Animal Learning \& Behavior, 23, 144-153.

Denniston, J. C., Cole, R. P., \& Miller, R. R. (1998). The role of temporal variables in the transfer of conditioned inhibition. Journal of $E x$ perimental Psychology: Animal Behavior Processes, 24, 200-214.

DESMONd, J. E., \& MoORE, J. W. (1988). Adaptive timing in neural networks: The conditioned response. Biological Cybernetics, 58, 405-415.

GibBon, J., \& BalsaM, P. (1981). Spreading association in time. In C. M. Locurto, H. S. Terrace, \& J. Gibbon (Eds.), Autoshaping and conditioning theory (pp. 219-253). New York: Academic Press.

GoDDARD, M. J. (1995). Acquisition of US-no US associations in Pavlovian conditioning. Learning \& Motivation, 26, 264-277.

Hallam, S. C., Matzel, L. D., Sloat, J., \& Miller, R. R. (1990). Excitation and inhibition as a function of posttraining extinction of the excitatory cue used in Pavlovian inhibition training. Learning \& Motivation, 21, 59-84.

Holland, P. C. (1984). Differential effects of reinforcement of an inhibitory feature after serial and simultaneous feature negative discrimination training. Journal of Experimental Psychology: Animal Behavior Processes, 10, 461-475.

Holland, P. C. (1989). Transfer of negative occasion setting and conditioned inhibition across conditioned and unconditioned stimuli. Journal of Experimental Psychology: Animal Behavior Processes, 15, 311-328.

Holland, P. C. (1992). Occasion setting in Pavlovian conditioning. In D. Medin (Ed.), The psychology of learning and motivation (Vol. 28, pp. 69-125). San Diego: Academic Press.

Holland, P. C., Hamlin, P. A., \& Parsons, J. P. (1997). Temporal specificity in serial feature-positive discrimination learning. Journal of Experimental Psychology: Animal Behavior Processes, 23, 95-109.

Holland, P. C., \& LamarRe, J. (1984). Transfer of inhibition after serial and simultaneous feature negative discrimination training. Learning \& Motivation, 15, 219-243.

KilleEN, P. R., \& FetTERMAn, J. G. (1988). A behavioral theory of timing. Psychological Review, 95, 274-295.

Lamarre, J., \& Holland, P. C. (1987). Transfer of inhibition after serial feature negative discrimination training. Learning \& Motivation, 18, 319-342

LySLE, D. T., \& Fowler, H. (1985). Inhibition as a "slave" process: Deactivation of conditioned inhibition through extinction of conditioned excitation. Journal of Experimental Psychology: Animal Behavior Processes, 11, 71-94.
Matzel, L. D., Held, F. P., \& Miller, R. R. (1988). Reexamination of simultaneous and backward conditioning: Implications for contiguity theory. Learning \& Motivation, 19, 317-344.

Miller, R. R., \& BaRnet, R. C. (1993). The role of time in elementary associations. Current Directions in Psychological Science, 2, 106-111.

MilleR, R. R., \& MATZEL, L. D. (1988). The comparator hypothesis: A response rule for the expression of associations. In G. H. Bower (Ed.), The psychology of learning and motivation (Vol. 22, pp. 51-92). San Diego: Academic Press.

Miller, R. R., \& Schachtman, T. R. (1985). Conditioning context as an associative baseline: Implications for response generation and the nature of conditioned inhibition. In R. R. Miller \& N. E. Spear (Eds.), Information processing in animals: Conditioned inhibition (pp. 51-88). Hillsdale, NJ: Erlbaum.

Pavlov, I. P. (1927). Conditioned reflexes (G. V. Anrep, Trans.). London: Oxford University Press.

Rescorla, R. A. (1967). Inhibition of delay in Pavlovian fear conditioning. Journal of Comparative \& Physiological Psychology, 64, 114-120.

Rescorla, R. A. (1969). Pavlovian conditioned inhibition. Psychological Bulletin, 72, 77-94.

Rescorla, R. A. (1985). Conditioned inhibition and facilitation. In R. R. Miller \& N. E. Spear (Eds.), Information processing in animals: Conditioned inhibition (pp. 299-326). Hillside, NJ: Erlbaum.

Rescorla, R. A., \& Wagner, A. R. (1972). A theory of Pavlovian conditioning: Variations in the effectiveness of reinforcement and nonreinforcement. In A. H. Black \& W. F. Prokasy (Eds.), Classical conditioning II: Current research and theory (pp. 64-99). New York: Appleton-Century-Crofts.

ROBERTS, S. (1981). Isolation of an internal clock. Journal of Experimental Psychology: Animal Behavior Processes, 7, 242-268.

Savastano, H. I., Yin, H., Barnet, R. C., \& Miller, R. R. (1998). Temporal coding in Pavlovian conditioning: Hall-Pearce negative transfer. Quarterly Journal of Experimental Psychology, 513, 139-153.

Williams, D. A., Overmier, J. B., \& LoLordo, V. M. (1992). A reevaluation of Rescorla's early dictums about Pavlovian conditioning. Psychological Bulletin, 111, 275-290.

Williams, D. A., Travis, G. M., \& Overmier, J. B. (1986). Withincompound associations modulate the relative effectiveness of differential and Pavlovian conditioned inhibition procedures. Journal of Experimental Psychology: Animal Behavior Processes, 12, 351-362.

(Manuscript received September 19, 1997; revision accepted for publication March 24, 1998.) 